\title{
CULTURA DO EMPREENDEDORISMO: UM IMPERATIVO PARA A EDUCAÇÃO?
}

\author{
Ademir Henrique Manfré \\ Universidade do Oeste Paulista - UNOESTE, Faculdade de Ciências e Letras de Presidente Prudente, Presidente \\ Prudente, SP. E-mail: ademirmanfre@yahoo.com.br
}

\section{RESUMO}

Este ensaio é fruto de atividades ligadas à prática docente e à pesquisa científica desenvolvidas junto aos cursos de graduação de uma universidade privada do interior de São Paulo. Dentre as atividades, destacamos as reflexões oriundas de investigações teórico-metodológicas realizadas em bases de dados científicas, tais como BDTD, Scielo e também de orientações de pesquisas. Este ensaio analisa a temática da cultura do empreendedorismo e suas ressonâncias na atualidade. Como resultado, afirmamos que a contemporaneidade, ao impor padrões comportamentais de base empresarial baseados em aspectos como competitividade e produtividade, normatizam os espaços sociais, aniquilando a produção das diferenças a partir de regras ditatoriais impostas pela Indústria Cultural, reduzindo as possibilidades de crítica. Concluímos que a Teoria Crítica emerge como um referencial teórico que contempla a possibilidade de desenvolver em bases diferentes a análise do processo social em que se insere a educação escolar e seus vínculos com a cultura do empreendedorismo.

Palavras-chave: empreendedorismo. Educação. Indústria Cultural. Semiformação.

\section{THE CULTURE OF ENTREPRENEURSHIP: AN IMPERATIVE FOR EDUCATION?}

\begin{abstract}
This essay is the result of activities related to teaching practice and scientific research developed with Undergraduate courses of a private university in the mid-state of São Paulo. Among the activities, we highlight the reflections from theoretical and methodological investigations carried out in scientific databases, such as BDTD, Scielo and research guidelines. This essay analyzes the theme of the culture of entrepreneurship and its repercussion today. As a result, we affirm that the contemporaneity makes social spaces regular ones, annihilating the production of differences based on dictatorial rules imposed by the Cultural Industry. In other words, once imposing business-based behavioral patterns based on aspects such as competitiveness and productivity, contemporaneity is reducing the possibilities of criticism. We conclude that the Critical Theory emerges as a theoretical reference that contemplates the possibility of developing the analysis of the social process regarding different bases, in which school education and its links with the culture of entrepreneurship are inserted.
\end{abstract}

Keywords: Entrepreneurship. Education. Cultural Industry. Semiformation. 


\section{APRESENTAÇÃO: SITUAÇÃO DO DEBATE}

Este ensaio é fruto de atividades ligadas à prática docente e à pesquisa científica desenvolvidas junto aos cursos de graduação de uma universidade privada do interior do estado de São Paulo. Dentre essas atividades, são especialmente relevantes as discussões e reflexões oriundas de investigações teórico-metodológicas realizadas em base de dados científicas, tais como BDTD, Scielo e também de orientações de pesquisas científicas realizadas empiricamente. Desse modo, o presente ensaio analisa a temática da cultura do empreendedorismo e suas ressonâncias na atualidade. Para tanto, a presente investigação está pautada em conceitos provenientes da Teoria Crítica da Escola de Frankfurt, tais como Indústria Cultural, racionalidade instrumental e semiformação.

$\mathrm{Na}$ contemporaneidade, com o advento de um padrão comportamental de base empresarial e empreendedora, baseado em aspectos como competitividade, lucratividade e produtividade, o sucesso pessoal e profissional é o lugar almejado por todos. Nesses discursos e práticas, padronizações homogeneizadoras de comportamento se impõem e normatizam os espaços sociais, reduzindo a produção das diferenças a partir de regras ditatoriais impostas pelo mercado econômico, enfraquecendo as possibilidades de resistência e crítica à racionalidade instrumental presente nesses discursos.

Velocidade, racionalidade, competitividade, lucratividade, habilidades, produtividade, capacidade de aprender a aprender constantemente - muitas vezes desvinculadas do aprender a pensar -, capacidade de empreender são as marcas da contemporaneidade, afirma Bauman (1998).

De acordo com o referido, o período pós $2^{a}$ guerra foi palco de intensas mudanças e transformações na esfera social, política, cultural e educacional.

Entre elas, o fenômeno da globalização foi uma das mais evidentes transformações da paisagem social contemporânea. As novas tecnologias digitais, a nanotecnologia, a microeletrônica, o progresso científico transformaram as relações humanas de várias formas.

E a educação escolar não escapa a esse contexto.

Por exemplo, o trabalho, que antes se ancorava em um processo de aprendizagem por imitação ou tradição, transmitida de geração em geração, no momento atual se designa de forma especializada, técnica e formal nas escolas devido ao progressivo aumento da complexidade das tarefas laborais no tocante ao processo de industrialização.

Para Bauman (2001, p. 75), as relações sociais transformam-se, tornam-se instáveis, e o indivíduo agora se encontra "livre" para buscar sua especialização mediantes suas próprias forças.

O mundo cheio de possibilidades é como uma mesa de buffê com tantos pratos deliciosos que nem o mais delicado comensal poderia esperar provar de todos. Os comensais são consumidores, e a mais custosa e irritante das tarefas que se pode pôr diante de um consumidor é a necessidade de estabelecer prioridades: a necessidade de dispensar algumas opções e abandoná-las. "Será que utilizei os meios à minha disposição da melhor maneira possível?" é a pergunta que mais assombra e causa insônia ao consumidor.

Diante do exposto, a contemporaneidade exige dos indivíduos performances sucessivas, tendo estas as características principais da valorização da competitividade, especialidades e do "espírito empreendedor": que vença o melhor, o mais esforçado, o mais preparado. Esse é o ponto nodal do estilo de existência estimulado pela contemporaneidade.

Esse rápido panorama nos faz pensar sobre vários aspectos pelos quais se constitui o indivíduo e a sua subjetividade ${ }^{1}$.

\footnotetext{
${ }^{1}$ Bezerra JR. (2010) desenvolve uma importante reflexão sobre os modos de subjetivação contemporâneos. Para o referido, a subjetividade é concebida como emergência histórica de processos em coerência com os processos sociais, culturais, econômicos, midiáticos, tecnológicos que participam de sua constituição e funcionamento. Entre as formas de subjetivação na atualidade, o autor destaca a negação do sofrimento, a busca irrefreável da felicidade, a instrumentalização do pensamento e a administração da vida.
} 
Esse movimento torna-se uma obrigação, um imperativo na atualidade, concebe Bauman (2001). Não chegamos a pensar em "por que mudar", "por que assumir", "por que desejar" e "por que flexibilizar". Somente sabemos que o movimento e a atualização constantes são fundamentais para que o indivíduo tente evitar ficar para trás, tornar-se descartado, "excluído".

\section{METODOLOGIA: OS CAMINHOS TRILHADOS}

Este ensaio é fruto de atividades ligadas à prática docente e à pesquisa científica por mim desenvolvida junto aos cursos de graduação de uma universidade privada do interior do Estado de São Paulo. A análise metodológica consistiu em discussões e reflexões oriundas de investigações teórico-metodológicas realizadas em base de dados científicas, tais como BDTD e Scielo e também de orientações de pesquisas científicas e estágios de pesquisa. Como proposta analítica, pautamonos em autores filiados à Teoria Crítica da Escola de Frankfurt, os quais forneceram os elementos de crítica para o debate proposto. Ancoramo-nos em conceitos provenientes da Teoria Crítica da Escola de Frankfurt, tais como: Indústria Cultural, Racionalidade instrumental e semiformação.

\section{DISCUSSÃO: A PERFORMANCE DO INDIVÍDUO CONTEMPORÂNEO}

Além dos aspectos anteriormente mencionados, a contemporaneidade, regida sob as égides do capitalismo e do consumo exacerbado tem em suas mercadorias e produtos a matériaprima básica para a produção e criação da cultura empreendedora.

A cultura do empreendedorismo que assola nossa sociedade não é um mal em si mesmo, inclusive ela até poderia ser um modo de existência resistindo dentro de outro registro histórico. A questão é que o modo pelo qual ela atua em nossa sociedade é endêmica, viral, age por contágio, quase que impossível de escapar. Características como proatividade, inventividade, senso de oportunidade, flexibilidade e polivalência formam o que chamaríamos hoje de marcas do empreendedor. Este é inventado desde tenra infância, para na fase produtiva, estar apto a atuar no mercado de trabalho. Porém, para estar fadado ao sucesso, o empreendedor deve investir constantemente em si mesmo, isto é, existe todo um aparato educacional para suprir, reciclar e conformar esse ethos empresarial (MORENO FILHO, 2015, p. 655).

Sempre na direção da rapidez, da velocidade, o consumir - ideias, imagens, produtos, mercadorias, estilos de vida - no sentido de nos tornar mais criadores com uma gama maior de possibilidades, ganha enorme importância para os indivíduos que queiram se tornar empreendedores.

Debórd $(1997$, p. 13) retrata um contexto em que os meios de comunicação de massa atingem um estado de desenvolvimento tão avançado que fazem da imagem, da aparência e da cultura empreendedora o valor mais importante a ser almejado.

Toda a vida das sociedades nas quais reinam as modernas condições de produção se apresenta como uma imensa acumulação de espetáculos. Tudo o que era vivido diretamente tornou-se uma representação. As imagens que se destacaram de cada aspecto fundem-se num fluxo comum, no qual a unidade dessa mesma vida já não pode ser restabelecida. A realidade considerada parcialmente apresenta-se em sua própria unidade geral como um pseudomundo à parte, objeto de mera contemplação.

No espetáculo, a imagem é tudo: sou empreendedor, produtor, competitivo, especialista, polivalente.

A sociedade performática - e por que não dizer empreendedora - obtém seus artefatos do capitalismo exacerbado para compor seu cenário glamouroso e espetacular dos indivíduos. Desse modo, a possibilidade de participar satisfatoriamente no palco forjado socialmente depende da alta capacidade empreendedora dos indivíduos, concebe Debórd (1997). E empreender mais, cada 
vez mais e mais, pois esta é a performance que o sistema demanda de seus consumidoresprodutores.

Nessa cultura de estetização do eu, o indivíduo tem seu valor atribuído pelo o que aparenta ser mediante as imagens produzidas para se apresentar na cena social e, dessa forma, a exibição se transforma no lema essencial da existência.

Esse é o cenário onde se desvelam as experiências características de nosso tempo, onde os indivíduos se posicionam de maneira peculiar no espaço da sociabilidade, desenhando assim, um autorretrato de nossos dias. Gadilha (2009, p. 149) conclui que "o indivíduo moderno, a que se qualificava como sujeito de direitos, transmuta-se, assim, num indivíduo microempresa: Você $S / A^{\prime \prime}$.

Nesse contexto, o indivíduo vive o dilema da tentativa de pertencer e ser reconhecido pela sociedade.

Diante da amplitude que caracteriza a temática, as condições que constituem o cenário espetacular contemporâneo propiciam a formação de subjetividades identificadas com o próprio contexto do espetáculo. A lei do consumo nos dita o que é preciso comprar, consumir, adquirir, se especializar, ser empreendedor, fazendo de um objeto não presente no cotidiano do indivíduo algo indispensável. Esse panorama, de acordo com Costa (2004) e Bauman (2001) traz uma roupagem diferente para a sensação de aceitação do sujeito por parte do outro.

O sujeito é capturado pela ideia de que só será aceito pelo outro quando corresponder ao modelo que a ele está sendo solicitado naquele momento. O resultado desse contexto é o vazio, a angústia, o sentimento de fracasso diante de uma sociedade que exige a especialização intensa e o protagonismo da cultura empreendedora. Se eu não tenho capacidade de empreender, eu sou um desajustado - e por que não dizer fracassado - na sociedade espetacular.

\section{RESULTADOS: E A EDUCAÇÃO, QUAL LUGAR ELA OCUPA NESSE CENÁRIO?}

No cenário descrito, a educação torna-se um elemento imprescindível na configuração de novas subjetividades. Em termos de políticas públicas educacionais, por exemplo, os investimentos na escola têm como objetivo formar, ou melhor, qualificar capital humano. Dito de outro modo, tais políticas ensejam formatar um modelo de indivíduo competitivo, produtivo, qualificador e empreendedor. Várias reformas educacionais possuem esse objetivo, como por exemplo, a lei de reforma do ensino médio, lei n. 13 415/17.

Quais consequências esse modo de existir sugere?

Não a formação de um indivíduo livre, autônomo, esclarecido, emancipado, mas, pelo contrário, a manutenção da ordem social com a qual obtém seu poder político e econômico, não permitindo mais fazer a experiência ${ }^{2}$ do pensar o próprio pensamento.

A possibilidade de o indivíduo e, consequentemente, a sociedade conquistarem certa autonomia por meio da formação cultural (Bildung) é irrisória. Porém, é vendida como uma realidade possível como se estivesse ao alcance de todos. Assiste-se, uma vez mais, à durabilidade da promessa iluminista: liberdade e autonomia versus controle e dominação.

Todo esse contexto de massificação culmina naquilo que Adorno (1996) chamou de semiformação. O principal desafio para Adorno é compreender como, apesar de toda a informação que hoje se difunde, a semiformação passou a ser a forma dominante da consciência.

\footnotetext{
${ }^{2}$ Tomamos como referência o conceito de experiência explorado por Larrosa (2002, p. 21): “A experiência é o que nos passa, o que nos acontece, o que nos toca. Não o que se passa, não o que acontece, ou o que toca. A cada dia se passam muitas coisas, porém, ao mesmo tempo, quase nada nos acontece".
} 


\section{CONCLUSÃO: COMO RESISTIR À CULTURA PERFOMÁTICA?}

O quadro que se apresenta para uma educação para a experiência formativa não é nada animador. Num dialogo com as ideias de Adorno (1995a, 1995b, 1995c), Gagnebin (2006) e Larrosa (2004) encontramos alguns elementos que nos ajudam a aprofundar o sentido da experiência formativa em educação, a qual reivindicamos com os autores aqui trabalhados.

Uma das formas indicadas pelo frankfurtiano para resistir à racionalidade instrumental ${ }^{3} \mathrm{da}$ cultura atual "é a autorreflexão crítica sobre a semiformação, em que necessariamente se converteu" (ADORNO, 1996, p. 410).

Em função disso, Adorno tece críticas à sociedade tecnológica moderna, a qual forma pessoas afinadas com a técnica. Pucci (1999, p. 112) considera que "o pensamento adorniano refuta tanto uma noção de progresso ingenuamente otimista, que acredita ter superado os irracionalismos míticos, como uma postura niilista que busca um retorno a uma natureza idílica que não mais existe".

O que assegura em Adorno (1996) o pensamento autorreflexivo é a autocrítica. Diante disso, pode-se afirmar que a função primeira do pensamento, e nisso encontramos mais uma contribuição do filósofo para o debate aqui proposto, é oferecer resistência ao status quo. Para Adorno (1996), a ciência e a Pedagogia deveriam se deter em uma análise mais pormenorizada sobre os modos como a disciplina, a fetichização da técnica e a instrumentalização do pensar se vinculam umas às outras na formação ou semiformação do indivíduo e, portanto, na impossibilidade da experiência formativa. Ao recuperar o sentido autorreflexivo e crítico do pensamento filosófico, Adorno (1995d) irá cobrar da educação o exercício da autorreflexão crítica a ser recuperada em nome da Pedagogia da Aufklärung e dos ideais de emancipação a serem preservados no tempo presente. Pagni \& Silva (2007, p. 256) afirmam que Adorno postula que o professor que "estivesse disposto a pensar o próprio ofício deveria compreender as condições sociais e políticas que envolvem a atividade e se empenhar na reflexão sobre seus limites no mundo totalmente administrado".

Em busca de uma alternativa ainda possível como um meio de resistência à racionalidade instrumental e à atitude irrefletida instaurada na educação escolar, assumimos o desafio de pensar uma educação que resgate nossa capacidade de criação e imaginação através de diferentes linguagens.

Procuramos destacar que a insistência em um pensamento capaz de pensar a si mesmo seria o início de uma resistência à sociedade administrada pela razão instrumental e, portanto, possibilitador de uma educação para a experiência formativa.

Diante disso, Adorno (1996) recomenda que a escola deve basear-se numa pedagogia do esclarecimento e da autoformação, em detrimento de uma pedagogia da subordinação ao caráter mercadológico e empresarial frisado pela produtividade e eficiência da racionalidade instrumental.

Finalizando essa discussão, a leitura e o esforço de compreensão dos textos frankfurtianos levou-nos a refletir sobre os propósitos educacionais atuais: aligeiramento da formação, tecnificação, produtividade, empreendedorismo.

\footnotetext{
3 Esse conceito é tomado das reflexões desenvolvidas por Adorno e Horkheimer (1985). Os autores resume, com riqueza, os elementos constitutivos da razão instrumental: "ela é razão no processo técnico, na operação, no saber aplicado. Reifica-se; coisifica-se. Eliminando toda a dubiedade do pensar através de sua unidimensionalidade [...]" (PUCCI, 1994, p. 24). Dito de outro modo, trata-se de uma racionalidade como expressão da capacidade do homem de ordenar a realidade pautada em fins e objetivos tecnicamente calculados previamente. Toda a ciência e a técnica se orientam para antecipar acontecimentos e prover as necessidades humanas.
} 


\section{REFERÊNCIAS}

ADORNO, Theodor W. \& HORKHEIMER, Max. Dialética do esclarecimento: fragmentos filosóficos. Tradução de Guido Antônio de Almeida. Rio de Janeiro: Zahar ed., 1985.

ADORNO, Theodor W. Educação após Auschwitz. In: Theodor Adorno: educação e emancipação. Tradução de Wolfgang Leo Maar. Rio de Janeiro: Paz e Terra, 1995a, p. 119-138.

. Educação...para quê? In: Theodor Adorno: educação e emancipação. Tradução de Wolfgang Leo Maar. Rio de Janeiro: Paz e Terra, 1995b, p. 139-154.

. O que significa elaborar o passado? In: Theodor Adorno: educação e emancipação. Tradução de Wolfgang Leo Maar. Rio de Janeiro: Paz e Terra, 1995c, p. 29-50.

. Teoria da Semicultura. Tradução de Newton RAMOS-DE-OLIVEIRA; Bruno Pucci; Cláudia B. M. Abreu. Educação e Sociedade, n. 56, Campinas, São Paulo: Papirus, dez. 1996, p. 388-441.

BAUMAN, Zygmunt. O mal-estar na pós-modernidade. Tradução de Mauro Gama e Cláudia Martineli Gama. Rio de Janeiro: Jorge Zahar ed., 1998.

. Modernidade líquida. Tradução de Plínio Dentzien. Rio de Janeiro: Jorge Zahar ed., 2001.

BEZERRA JR., Benilton. A psiquiatria e a gestão tecnológica do bem-estar. In: FILHO, João F. (Org). Ser feliz hoje: reflexões sobre o imperativo da felicidade. Rio de Janeiro: Ed. FGV, 2010, p. 117-134.

BIRMAN, Joel. O mal-estar na atualidade: a psicanálise e as novas formas de subjetivação. Rio de janeiro: Civilização Brasileira, 2009.

COSTA, Jurandir F. O vestígio e a aura: corpo e consumismo na moral do espetáculo. Rio de Janeiro: Garamond, 2004.

DEBÓRD, GY. A sociedade do espetáculo. Rio de Janeiro: Contraponto, 1997.

GADELHA, Sylvio. Biopolítica, governamentabilidade e educação: introdução e conexões a partir de Michel Foucault. Belo Horizonte: ed. Autêntica, 2009.

GAGNEBIN, Jeanne M. Memória, história, testemunho. In: . Lembrar, escrever, esquecer. São Paulo: Ed. 34, 2006, p. 49-57.

LARROSA, Jorge. Ensaios eróticos - experiência e paixão. In: . Linguagem e educação depois de Babel. Belo Horizonte: Ed. Autêntica, 2004, p. 151-165.

. Notas sobre a experiência e o saber da experiência. Revista Brasileira de Educação, n. 19, São Paulo, jan./abr. 2002, p. 20-28.

MORENO FILHO, José W. N. Cultura do empreendedorismo: modo de vida e microfascismo contemporâneo. Anais do VI SIEF: Simpósio Internacional em Educação e Filosofia. Universidade Estadual Paulista/FCT, Presidente Prudente/SP, 2015, p. 651-661, ISSN: 2176-1957. 
PAGNI, Pedro A.; SILVA, Divino J. A crítica da cultura e os desafios da Educação após Auschwitz: uma leitura a partir da Teoria Crítica da Escola de Frankfurt. In: (orgs.). Introdução à Filosofia da Educação: temas contemporâneos e história. São Paulo: Avercamp, 2007, p. 243-271.

PUCCI, Bruno. A teoria da semicultura e suas contribuições para a Teoria Crítica da educação. In: ZUIN, Antônio A. S.; PUCCI, Bruno; RAMOS-DE-OLIVEIRA, Newton (orgs.). A educação danificada: contribuições à Teoria Crítica da Educação. Petrópolis, Rio de Janeiro: Vozes, 1999, p. 89-113.

PUCCI, Bruno; ZUIN, Antônio A. S.; RAMOS-DE-OLIVEIRA, Newton. Adorno: o poder educativo do pensamento crítico. Petrópolis, Rio de janeiro: Vozes, 1994. 